Original

\title{
Immunohistochemical expression of podoplanin in so-called hard $\alpha$-keratin-expressing tumors, including calcifying cystic odontogenic tumor, craniopharyngioma, and pilomatrixoma
}

\author{
Kentaro Kikuchi1), Shigeru Ito'), Harumi Inoue1), Patricia González-Alva1), \\ Yuji Miyazaki1), Hideaki Sakashita'2), Atsuo Yoshino ${ }^{3)}$, Yoichi Katayama3), \\ Tadashi Terui ${ }^{4)}$, Fumio Ide ${ }^{1)}$ and Kaoru Kusamal) \\ 1)Division of Pathology, Department of Diagnostic and Therapeutic Sciences, \\ Meikai University School of Dentistry, Sakado, Japan \\ 2)Second Division of Oral and Maxillofacial Surgery, Department of Diagnostic and Therapeutic Sciences, \\ Meikai University School of Dentistry, Sakado, Japan \\ ${ }^{3)}$ Department of Neurological Surgery, Nihon University School of Medicine, Tokyo, Japan \\ 4)Division of Cutaneous Science, Department of Dermatology, Nihon University School of Medicine,
}

Tokyo, Japan

(Received 1 March and accepted 12 April 2012)

\begin{abstract}
Podoplanin, a transmembrane sialomucin-like glycoprotein, is a specific marker of lymphatic vessels, and its expression is also considered to be associated with tumor invasion and tooth development. In this study, we examined the expression of podoplanin in calcifying cystic odontogenic tumor (CCOT) in comparison with that in other so-called hard $\alpha$-keratin-expressing tumors such as craniopharyngioma (CP) and pilomatrixoma (PM). Immunohistochemical staining for podoplanin was carried out using surgical specimens of 15 CCOTs of the jaw, 19 CPs of the pituitary gland, and 15 PMs of the skin. Positivity for hard $\alpha$-keratin was evident in ghost, shadow and transitional cells in all of these tumors $(100 \%)$. The podoplanin expression in CCOTs
\end{abstract}

Correspondence to Dr. Kentaro Kikuchi, Division of Pathology, Department of Diagnostic and Therapeutic Sciences, Meikai University School of Dentistry, 1-1 Keyakidai, Sakado, Saitama 350-0283, Japan

Tel: +81-049-279-2773

Fax: +81-049-286-6101

E-mail: k-kikuchi@dent.meikai.ac.jp was evident in the periphery of ameloblastoma-like epithelium (86.6\%) and the epithelial cells adjacent to ghost cells $(60 \%)$. On the other hand, in adamantinomatous-type CPs, podoplanin expression was observed in epithelial components corresponding to the stratum intermedium (100\%), but not in the periphery of ameloblastoma-like epithelium (0\%). In squamoustype CPs podoplanin was expressed in basal cells $(100 \%)$, but all of the PMs were podoplanin-negative $(0 \%)$. In the periphery of the ameloblastoma-like epithelium or basophilic cell layer, podoplanin was expressed more strongly in CCOTs than in CPs or PMs. These findings suggest that the expression of podoplanin in CCOTs may reflect rapid turnover of cytoskeletal filaments and local invasiveness. (J Oral Sci 54, 165-175, 2012)

Keywords: podoplanin; hard $\alpha$-keratin; calcifying cystic odontogenic tumor; craniopharyngioma; pilomatrixoma. 


\section{Introduction}

Calcifying odontogenic cyst (COC) was first described by Gorlin et al. (1) in 1962 as a specific histological entity. In 1971, the World Health Organization (WHO) described COC as a "non-neoplastic" cystic lesion (2). Thereafter, in 1992, COC was classified as an odontogenic tumor (3). In the latest WHO classification, published in 2005, the term $\mathrm{COC}$ was changed to calcifying cystic odontogenic tumor (CCOT) to reflect its neoplastic nature (4). CCOT is a benign cystic odontogenic neoplasm characterized by proliferation of ameloblastoma-like epithelium with ghost cells, local invasiveness and a rare tendency for recurrence (5). Although some studies have described the clinical and histopathological features of COC, those studies focused on its immunohistochemical profile, and few investigations have addressed its proliferative activity (6-8). The mechanisms involved in the progres- sion and invasiveness of CCOT are still unknown.

Expression of podoplanin has been found in various neoplasms, and its association with invasiveness has been suggested, in view of the ability of the protein to induce actin remodeling in tumor cells (9-14). The purpose of the present study was to examine the localization of podoplanin in CCOT and to clarify the role of the protein.

Human podoplanin (T1 $\alpha-2$, aggrus or gp36) is a 38-kDa type-1 transmembrane sialomucin-like glycoprotein consisting of 162 amino acids, nine of which form its intracellular domain. Although the protein has been considered a specific marker of lymphatic endothelial cells (15-19), its expression has also been demonstrated in various normal as well as neoplastic tissues (9-14). In addition, it has been reported that podoplanin expression is biologically related to cell migration and invasion (20-22). In odontogenic lesions, we have previously shown that podoplanin is expressed in ameloblastoma,
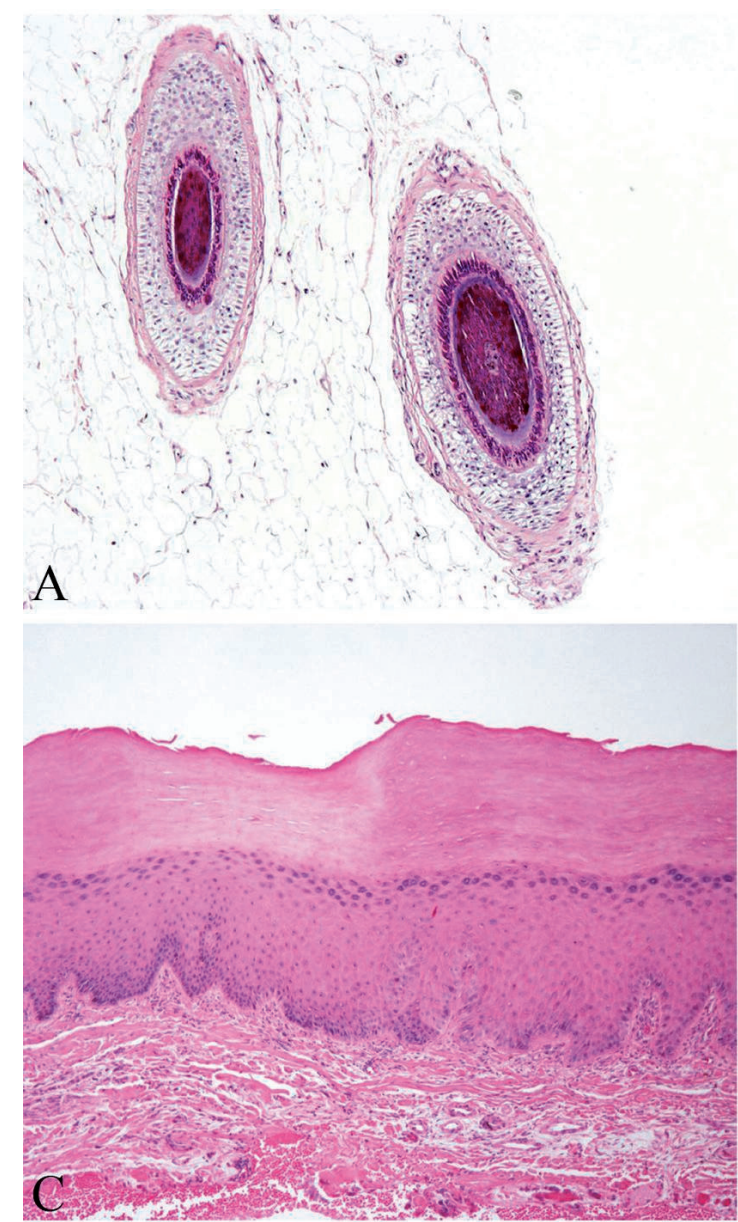
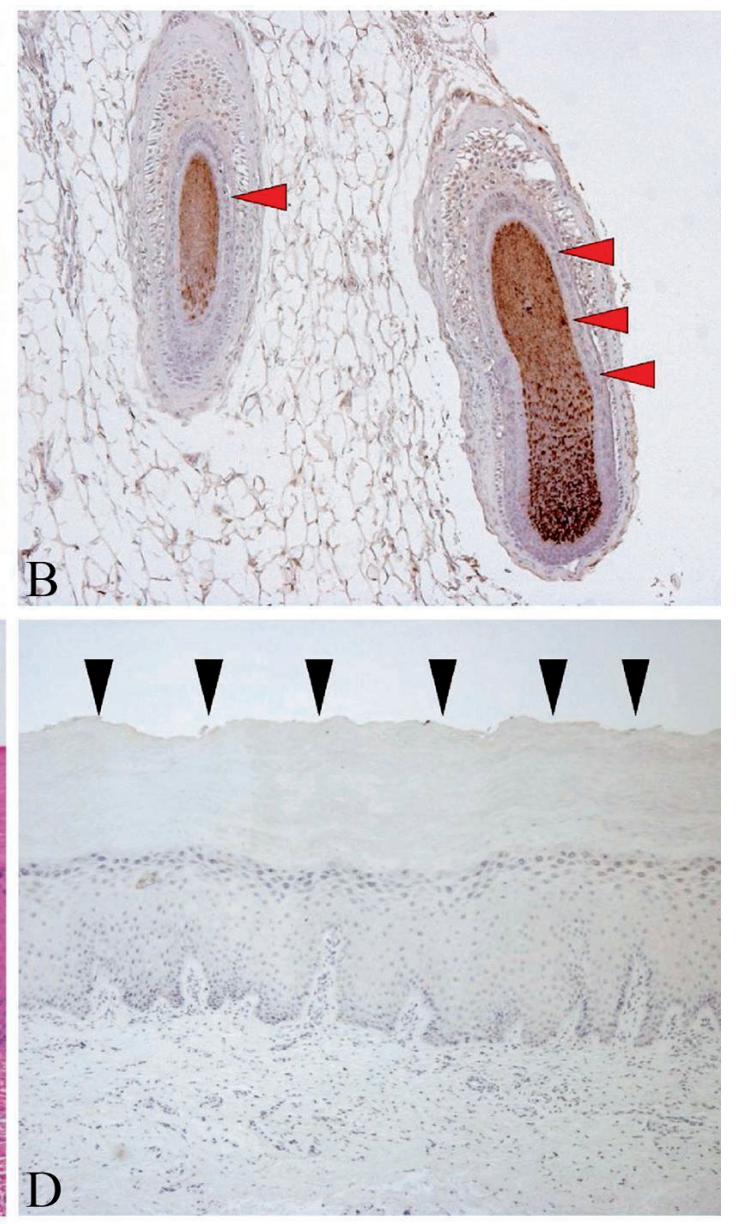

Fig. 1 Scalp skin hair follicles and oral leukoplakias were used as positive and negative controls for hard $\alpha$-keratin, respectively ( $\times 200$ magnification). (A) H\&E staining of scalp skin hair follicles; (B) strong immunoreactivity for hard $\alpha$-keratin was detected in the cortex of the hair shafts (red arrowheads); (C) H\&E staining of oral leukoplakia; (D) immunoreactivity for hard $\alpha$-keratin was not detected in the hyperkeratotic layer (black arrowheads). 
keratocystic odontogenic tumor, and odontoma (23-25).

In the present study using immunohistochemical methods, we analyzed the expression of podoplanin in CCOT to evaluate the correlation between podoplanin and the neoplastic character of the tumor. In addition to CCOT, two other tumor types are known to display ghost cells or their homologue, shadow cells: adamantinomatous craniopharyngioma (CP) of the pituitary gland (26) and pilomatrixoma (PM) of the skin (27), which are tumors expressing hard $\alpha$-keratin (28). The expression pattern of podoplanin in CCOT was compared with that in $\mathrm{CP}$ and $\mathrm{PM}$, and the significance of the protein in these three tumor types was considered.

\section{Materials and Methods}

\section{Tissue samples}

Formalin-fixed, paraffin-embedded tissue samples from 15 cases of CCOT, 19 cases of CP, and 15 cases of PM were used. Sections of normal head skin, oral mucosa, oral leukoplakia and hemangioma were used as control samples. Each section was prepared for immunohistochemical analysis.

\section{Immunohistochemical analysis}

Deparaffinized sections were immersed in absolute methanol containing $0.3 \% \mathrm{H}_{2} \mathrm{O}_{2}$ for $20 \mathrm{~min}$ at room temperature to block endogenous peroxidase activity. After washing with phosphate-buffered saline (PBS, 0.01 M phosphate buffer, $0.15 \mathrm{M} \mathrm{NaCl}, \mathrm{pH}$ 7.4), the sections were incubated in $2 \%$ bovine serum albumin in PBS for $15 \mathrm{~min}$ at room temperature to block nonspecific reactions. Appropriately diluted rabbit polyclonal antibody against hard $\alpha$-keratin $(10 \mu \mathrm{g} / \mathrm{mL}, 1: 400)$ (28) was applied to each section for $60 \mathrm{~min}$ at room temperature. After washing with PBS the slides were incubated with a prediluted anti-rabbit IgG antibody conjugated with peroxidase (Nichirei, Tokyo, Japan) for $30 \mathrm{~min}$ at room temperature. After washing with PBS, the sections were immersed for $10 \mathrm{~min}$ in $0.05 \%$ 3,3'-diaminobenzidine tetrahydrochloride (DAB, Sigma Chemical Industries, St. Louis, MO, USA) in $0.05 \mathrm{M}$ Tris-HCl buffer ( $\mathrm{pH}$ 7.6) containing $0.01 \% \mathrm{H}_{2} \mathrm{O}_{2}$. After washing with PBS, an appropriately diluted mouse monoclonal anti-human D2-40 (anti-podoplanin antibody; Dako North America, Inc., Carpinteria, CA, USA) was applied to each section for $60 \mathrm{~min}$ at room temperature, followed by a prediluted anti-mouse $\operatorname{IgG}$ antibody conjugated with peroxidase (Nichirei) for $30 \mathrm{~min}$ at room temperature. After washing with PBS, the sections were incubated with HistoGreen substrate (AbCys s.a., Paris, France) solution at room temperature until a sufficient color intensity had been attained within 1-5 min. After another wash with PBS, the sections were counterstained with Mayer's hematoxylin.

The present study was performed with approval from the Research Ethics Committee of Meikai University School of Dentistry (A0832).

\section{Results \\ Expression of hard $\alpha$-keratin in CCOT, CP, and PM}

Immunoreactivity for hard $\alpha$-keratin was found in hair shafts of normal head skin (Fig. 1A, B) but not in the hyperkeratotic layer of oral leukoplakia (Fig. 1C, D). In all 15 CCOTs, hard $\alpha$-keratin was detected only in ghost cells (Fig. 2A-D), and not in any other epithelial components (Table 1) (Fig. 2E-I). Among the 19 cases of CP, 9 were the adamantinomatous type with shadow cells, and 10 were the squamous type without shadow cells (Table 1). A positive reaction was found only in shadow cells of the adamantinomatous type (Table 1) (Fig. 3A-D). Among the 15 cases of PM, 12 were at the early regressive stage and 3 were at the late regressive stage (Table 1). A positive reaction was found in the cytoplasm of transitional cells and shadow cells, but not in that of basophilic cells in all $12 \mathrm{PMs}$ at the early regressive stage (Fig. 4A, B). In the $3 \mathrm{PMs}$ at the late regressive stage, bone metaplasia was evident, and immunoreactivity for hard $\alpha$-keratin was observed only in shadow cells (Table 1) (Fig. 4C, D). The immunostaining patterns for hard $\alpha$-keratin in CCOT, CP and PM are detailed in Table 2.

\section{Podoplanin expression in CCOT, CP, and PM}

Podoplanin was expressed only in lymphatic vessels of the normal oral mucosa (data not shown). In all 15 CCOTs, positivity for podoplanin was found mainly in marginal epithelial cells of tumor nests (Table 1), ameloblastoma-like epithelium (Fig. 2A, B), and proliferative areas of cord-like odontogenic epithelium (Fig. 2C, D). Sometimes, epithelial components adjacent to ghost cells were also positive for podoplanin (Table 1) (Fig. 2E, F). In one case of CCOT with odontoma, positivity for podoplanin was observed in pulp cells, odontoblasts and dentinal tubules of tooth-like structures (Fig. 2G-I).

Among the 19 cases of $\mathrm{CP}$, a positive reaction was found mainly in epithelial cells corresponding to the stratum intermedium in 9 of the adamantinomatous-type CPs (Fig. 3A-D), and expression of the protein was detected mainly in marginal basaloid cells of the 10 squamous-type CPs (Fig. 3E, F).

No podoplanin positivity was evident in any of the PMs (Table 1) (Fig. 4A, B). Immunoreactivity for podoplanin was found in osteoblast-like or osteocyte-like 

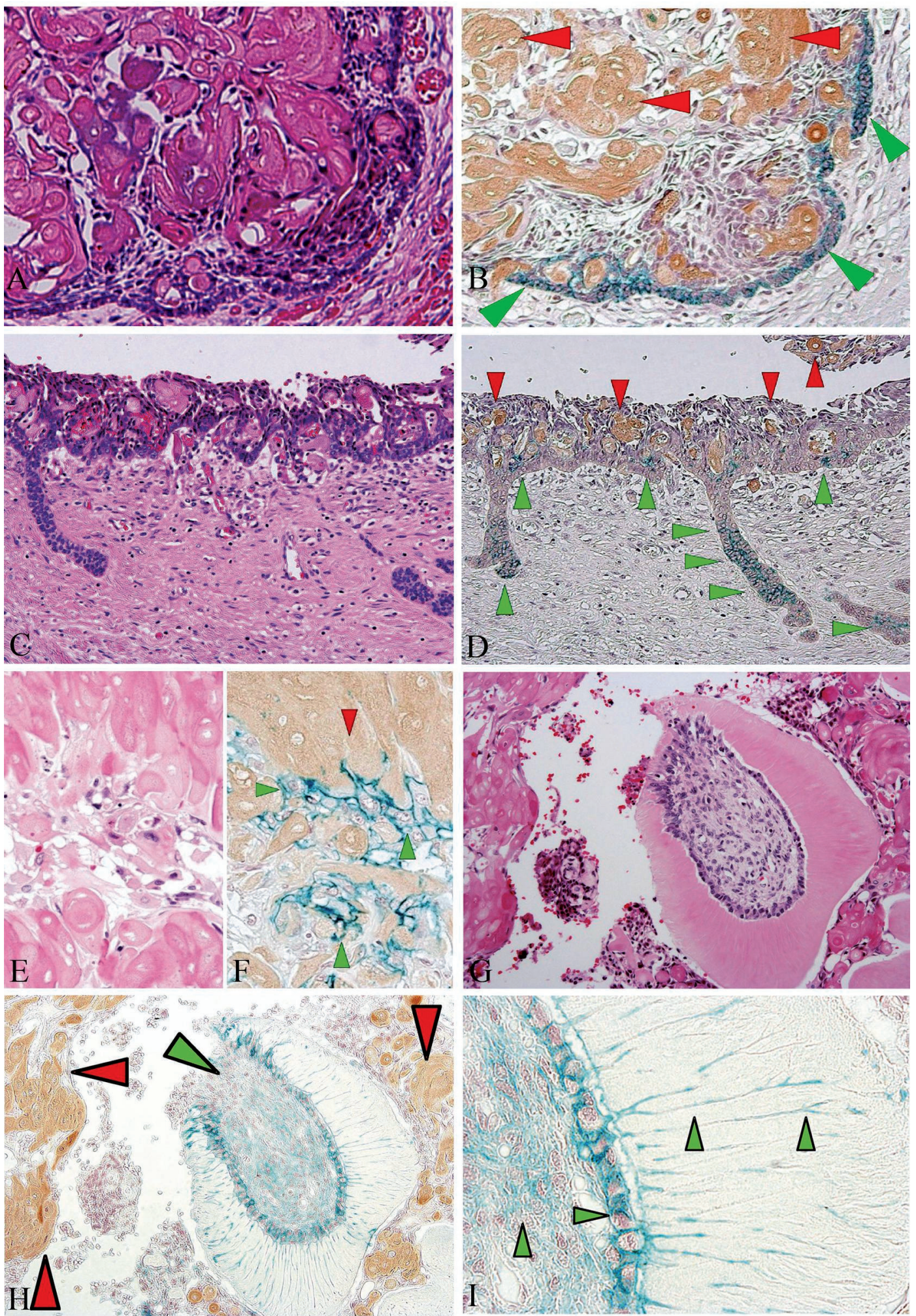

Fig. 2 Immunohistochemical double staining for hard $\alpha$-keratin and podoplanin in CCOT. (A) H\&E staining of CCOT $(\times 200$ magnification); (B) hard $\alpha$-keratin was observed in ghost cells (red arrowheads), and a positive reaction for podoplanin was evident in the peripheral epithelium of the tumor nest (green arrowheads); (C) H\&E staining of CCOT $(\times 200$ magnification); (D) positive reaction for podoplanin was evident at the strands of odontogenic epithelium and odontogenic small nests (green arrowheads); (E) high-power magnification of ghost cell nests in CCOT (H\&E stain, $\times 400$ magnification); (F) podoplanin-positive tumor epithelial cells (green arrowheads) located adjacent to ghost cells (red arrowhead); (G) H\&E staining of odontoma component in CCOT $(\times 100$ magnification); $(\mathrm{H})$ immunoreactivity for podoplanin (green arrowhead) and hard $\alpha$-keratin (red arrowheads); (I) high-power magnification shows podoplanin in the dental pulp, odontoblasts and intra-dentinal tubules of the tooth (green arrowheads) $(\times 400$ magnification). 
Table 1 Immunohistochemical staining for podoplanin and hard $\alpha$-keratin in calcifying cystic odontogenic tumors, craniopharyngiomas, and pilomatrixomas

\begin{tabular}{|c|c|c|c|c|c|c|c|c|c|c|c|c|}
\hline & \multicolumn{3}{|c|}{ CCOT } & \multicolumn{5}{|c|}{$\mathrm{CP}$} & \multicolumn{4}{|c|}{ PM } \\
\hline & GCs & t-Epi & GC-Epi & & SCs & t-Epi & SC-Epi & & SCs & SC-Epi & TCs & $\mathrm{BCs}$ \\
\hline 1 & - $\circ$ & $\square \bullet$ & $\square \bullet$ & 1 & - 0 & $\square \bullet$ & 口० & 1 & - $\circ$ & ND & - $\circ$ & $\square \bigcirc$ \\
\hline 2 & - 0 & $\square \bullet$ & $\square \bullet$ & 2 & - 0 & $\square \bullet$ & $\square ०$ & 2 & - 0 & ND & - 0 & $\square \circ$ \\
\hline 3 & - $\circ$ & $\square \bullet$ & $\square \bullet$ & 3 & - $\circ$ & $\square \bullet$ & 口० & 3 & - 0 & ND & - 0 & 口० \\
\hline 4 & - $\circ$ & $\square \bullet$ & $\square \bullet$ & 4 & - $\circ$ & $\square \bullet$ & $\square \bigcirc$ & 4 & - $\circ$ & ND & - $\circ$ & $\square \circ$ \\
\hline 5 & - 0 & $\square \bullet$ & $\square \bullet$ & 5 & - 0 & $\square \bullet$ & $\square \bigcirc$ & 5 & - 0 & ND & - 0 & $\square \bigcirc$ \\
\hline 6 & - 0 & $\square \bullet$ & $\square \bullet$ & 6 & - $\circ$ & $\square \bullet$ & $\square 0$ & 6 & - 0 & ND & - 0 & $\square \circ$ \\
\hline 7 & - 0 & $\square \bullet$ & $\square \bullet$ & 7 & - 0 & $\square \bullet$ & $\square \bigcirc$ & 7 & - 0 & ND & - 0 & $\square ०$ \\
\hline 8 & - $\circ$ & $\square \bullet$ & $\square \bullet$ & 8 & - $\circ$ & $\square \bullet$ & 口० & 8 & - $\circ$ & ND & - $\circ$ & $\square \bigcirc$ \\
\hline 9 & - 0 & $\square \bullet$ & $\square \bullet$ & 9 & a 0 & $\square \bullet$ & $\square 0$ & 9 & - 0 & $\square 0$ & - 0 & $\square \bigcirc$ \\
\hline 10 & - 0 & $\square \bullet$ & $\square \bigcirc$ & 10 & ND & $\square \bullet$ & ND & 10 & - 0 & 口० & - $\circ$ & $\square \bigcirc$ \\
\hline 11 & - $\circ$ & $\square \bullet$ & $\square \bigcirc$ & 11 & ND & $\square \bullet$ & ND & 11 & - 0 & $\square ०$ & - $\circ$ & $\square ०$ \\
\hline 12 & - $\circ$ & $\square \bullet$ & $\square \bigcirc$ & 12 & ND & $\square \bullet$ & ND & 12 & - 0 & ND & - $\circ$ & $\square \bigcirc$ \\
\hline 13 & - $\circ$ & $\square \bullet$ & $\square \bigcirc$ & 13 & ND & $\square \bullet$ & ND & 13 & - 0 & ND & ND & ND \\
\hline 14 & - 0 & ND & ND & 14 & ND & $\square \bullet$ & ND & 14 & - 0 & ND & ND & ND \\
\hline \multirow[t]{5}{*}{15} & - $\circ$ & ND & ND & 15 & ND & $\square \bullet$ & ND & 15 & - 0 & ND & ND & ND \\
\hline & & & & 16 & ND & $\square \bullet$ & ND & & & & & \\
\hline & & & & 17 & ND & $\square \bullet$ & ND & & & & & \\
\hline & & & & 18 & ND & $\square \bullet$ & ND & & & & & \\
\hline & & & & 19 & ND & $\square \bullet$ & ND & & & & & \\
\hline
\end{tabular}

CCOT; calcifying cystic odontogenic tumor, CP; craniopharyngioma, PM; pilomatrixoma, GCs; ghost cells, t-Epi; tumor epithelium, GC-Epi; epithelium adjacent to ghost cell, SCs; shadow cells, SC-Epi; epithelium adjacent to shadow cell, TCs; transitional cells, BCs; basophilic cells, hard $\alpha$-keratin ( $\bullet$ : positive, $\square$ : negative), podoplanin ( $\bullet$ : positive, $\circ$ : negative), ND; not detected, case numbers of 1 to 9 in $\mathrm{CP}$ are adamantinomatous types, and 10 to 19 in $\mathrm{CP}$ are squamous types. Case numbers of 1 to 12 in PM are at the early regressive stage, and 13 to 15 in PM are at the late regressive stage.

Table 2 Pattern of immunostaining for hard $\alpha$-keratin in calcifying cystic odontogenic tumor, craniopharyngioma, and pilomatrixoma

\begin{tabular}{lrl}
\hline Tumors & Reactivity & \multicolumn{1}{c}{ Positive cells } \\
\hline Calcifying cystic odontogenic tumor $(n=15)$ & $15 / 15(100 \%)$ & Ghost cells \\
& & \\
Craniopharyngioma $(n=19)$ & $9 / 9(100 \%)$ & Shadow cells \\
Adamantinomatous type $(n=9)$ & $0 / 10(0 \%)$ & \\
Squamous type $(n=10)$ & & \\
& & Transitional cells and shadow cells \\
Pilomatrixoma $(n=15)$ & $12 / 12(100 \%)$ & Shadow cells \\
Early regressive stage $(n=12)$ & $3 / 3(100 \%)$ & \\
Late regressive stage $(n=3)$ & & \\
\hline
\end{tabular}

cells at the late regressive stage (Fig. 4C, D). The pattern of immunostaining for podoplanin varied in CCOT, CP and PM (Table 3).

\section{Discussion}

CCOT is characterized by an ameloblastomatous epithelium with ghost cells that may calcify, local invasiveness and rare recurrence $(4,5)$. Other odontogenic tumors in which ghost cells appear as a secondary phenomenon include odontoma (29-35). With regard to the origin of ghost cells, it is thought that odontogenic epithelium undergoes metaplastic transformation with keratinization (32,33,35). Levy (29) has suggested that, in the course of metaplasia, squamous metaplasia likely occurs due to a reduction in the supply of oxygen, resulting in ischemic change, cell death and keratinization, thus leading to formation of ghost cells. One ultrastructural study has shown that although ghost cells 

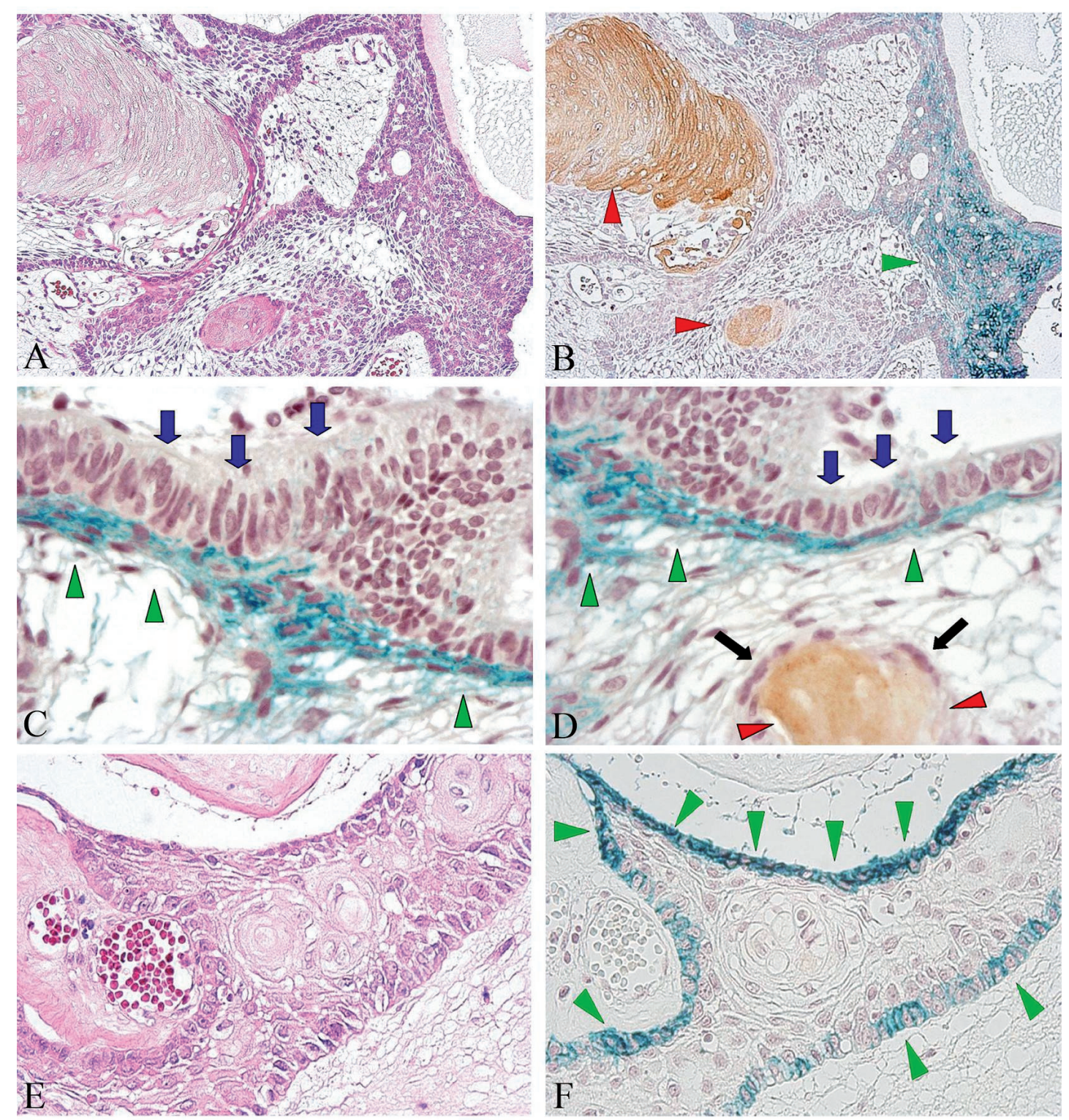

Fig. 3 Immunohistochemical double staining for hard $\alpha$-keratin and podoplanin in adamantinomatous-type or squamous-type CP. (A) H\&E staining of adamantinomatous-type CP ( $\times 100$ magnification); (B) hard $\alpha$-keratin was detected in shadow cells (red arrowheads) and positivity for podoplanin was observed mainly in the middle layer of adamantinomatous nests (green arrowhead); (C and D) high-power magnification of adamantinomatous-type CP, showing immunoreactivity for podoplanin in the middle-layer cells (green arrowheads), but not in the columnar epithelium (blue arrows) or epithelium (black arrows) adhering to shadow cells (red arrowheads) $(\times 400)$; (E) H\&E staining of squamous-type CP $(\times 200$ magnification); (F) immunoreactivity for podoplanin was strong in the basal layer of well differentiated squamous epithelium (green arrowheads), but immunoreactivity for hard $\alpha$-keratin was not evident.

lack keratohyaline granules, they do contain abundant tonofilaments and probably represent an altered form of keratin (33). In an immunohistochemical analysis, Piattelli and Trisi (35) demonstrated that ghost cells were negative for normal keratin. Furthermore, scanning electron microscopy studies have shown that the pattern formed by large tonofilament bundles in ghost cells is unlike that normally found in orthokeratinized or parakeratinized epithelium, and since the production of keratin is not a natural function of odontogenic epithelium, the ultrastructural features of ghost cell keratinization should be interpreted as indicating the production of an aberrant or unusual form of keratin, and not true keratin (29-31). However, CCOTs, including adamantinomatous-type $\mathrm{CP}$ and PM, express hard $\alpha$-keratin in ghost cells and shadow cells (28). Ghost cells in CCOT and shadow cells in adamantinomatous-type CP appear randomly, but shadow cells in PM appear through a shift of tran- 

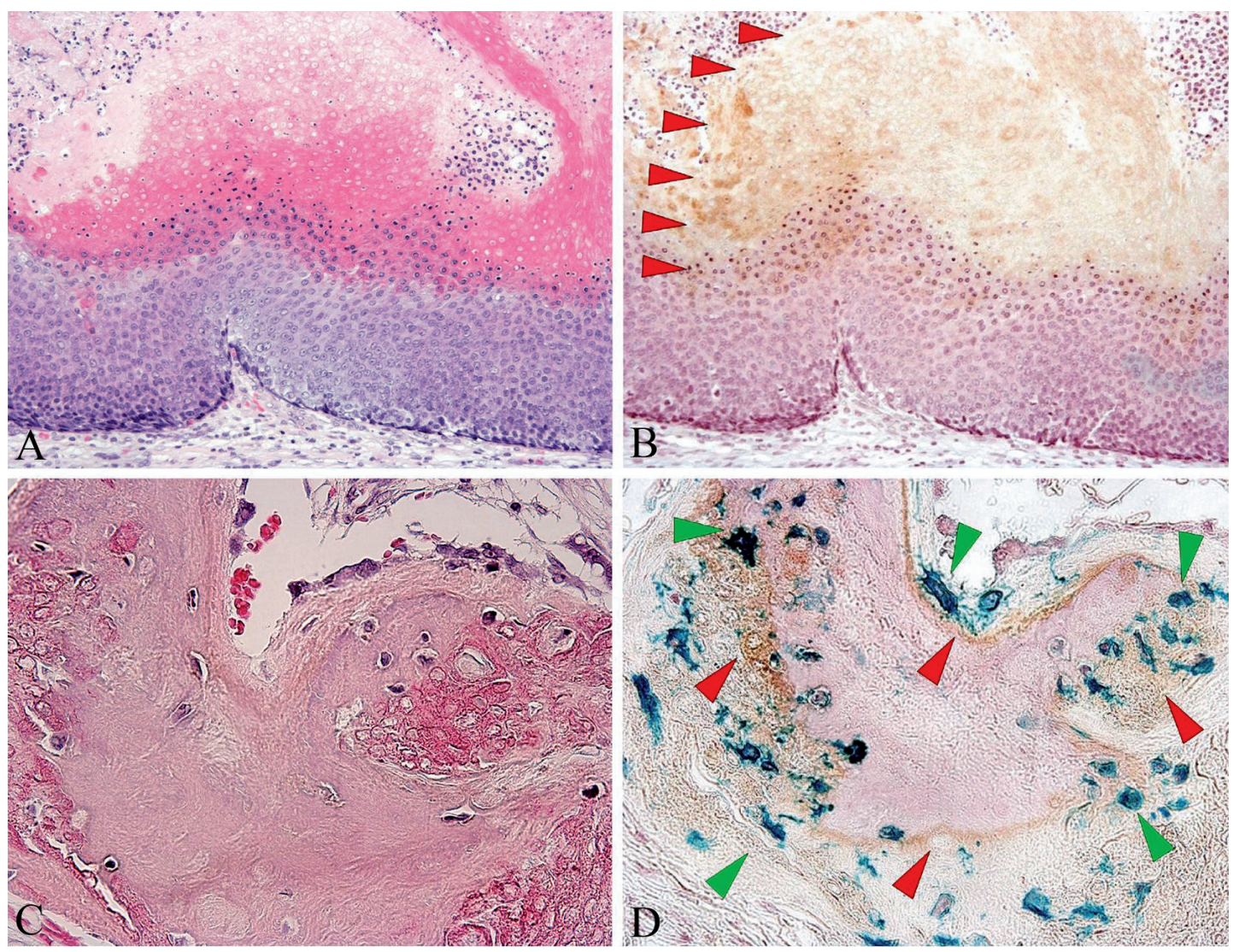

Fig. 4 Immunohistochemical double staining for hard $\alpha$-keratin and podoplanin in PM at the early and late regressive stages. (A) H\&E staining of early regressive-stage PM ( $\times 200$ magnification); (B) hard $\alpha$-keratin was detected in transitional and shadow cells (red arrowheads), but not in basophilic cells, and immunoreactivity for podoplanin was not evident in tumor nests. (C) H\&E staining of late regressive-stage PM ( $\times 400$ magnification); (D) positivity for podoplanin was observed in osteoblast-like cells on the calcified line and osteocyte-like cells in bone metaplastic lacunae (green arrowheads); hard $\alpha$-keratin was evident in shadow cells and the calcified line (red arrowheads).

Table 3 Pattern of immunostaining for podoplanin in calcifying cystic odontogenic tumor, craniopharyngioma, and pilomatrixoma

\begin{tabular}{lrl}
\hline Tumors & \multicolumn{1}{c}{ Reactivity } & \multicolumn{1}{c}{ Positive cells } \\
\hline Calcifying cystic odontogenic tumor $(n=15)$ & $13 / 15(86.6 \%)$ & $\begin{array}{l}\text { Periphery of ameloblastoma-like epitheliums } \\
\text { Epithelium adjacent to ghost cells }\end{array}$ \\
Craniopharyngioma $(n=19)$ & $9 / 15(60 \%)$ & \\
Adamantinomatous type $(n=9)$ & $0 / 9(0 \%)$ & $\begin{array}{l}\text { Periphery of ameloblastoma-like epitheliums } \\
\text { Non-periphery, stratum intermedium } \\
\text { (with odontoma }(n=1))\end{array}$ \\
Squamous type $(n=10)$ & $10 / 10(100 \%)$ & $\begin{array}{l}\text { Periphery, basal cell layer } \\
\text { Pilomatrixoma }(n=15)\end{array}$ \\
Early regressive stage $(n=12)$ & $0 / 12(0 \%)$ & $\begin{array}{l}\text { Non-positive tumor cells } \\
\text { Non-positive tumor cells (osteoblast or osteocyte-like cells } \\
\text { Late regressive stage }(n=3)\end{array}$ \\
& $0 / 3(0 \%)$ & were positive) \\
\hline
\end{tabular}

sitional cells. In CCOT, podoplanin-positive epithelial cells adjacent to ghost cells are thought to be pre-ghost cells with altered cytoskeletal remodeling that results in rapid degeneration. It has been reported that podoplanin increases the activities of Rho GTPases, mainly RhoA, thus contributing to cytoskeletal reorganization (20-22), whereas the mechanisms regulating denucleated ghost cells and shadow cells in CCOT, adamantinomatoustype CP and PM are unknown. Hibino et al. (36) have reported that in normal human skin, cells lose their nuclei and cytoplasmic organelles, a process known as terminal differentiation of keratinocytes, which is tightly 
regulated by the action of caspase-14. Further studies of keratinocyte denucleation in normal and tumor epithelium are needed to shed further light on this issue.

In CCOT, expression of podoplanin was observed mainly in the basal layer of the tumor epithelium and cord-like proliferative odontogenic epithelium. Similar patterns of immunoreactivity for podoplanin have been described in ameloblastoma or keratocystic odontogenic tumor $(23,24)$. Its expression might be related to cell migration and local invasion of odontogenic tumors. The expression of podoplanin is upregulated in a number of different human cancers, including those of the oral cavity, larynx, lung, uterine cervix, esophagus, skin, ovary and central nervous system $(9,10,12,19,37-40)$. With regard to the local invasiveness of CCOT, Gong et al. (7) have recently shown that MMP-9 in the stroma is associated with invasive ability. Although some reports, including our own, have described podoplanin expression in odontogenic tumors $(23-25,41)$, that in CCOT has not been documented. Our present study appears to be the first to have examined podoplanin expression in CCOT. We found that expression of podoplanin was present in the dental pulp, odontoblasts and intra-dental tubules of tooth-like structures in one case of CCOT associated with odontoma. Imaizumi et al. (42) and Sawa (43) have reported strong expression of podoplanin in enamel epithelia and odontoblasts in the bell stage tooth germ of the mouse. Our research group has recently identified positivity for podoplanin in developing and mature odontoblasts, Tomes fibers, and pulp cells near podoplanin-positive odontoblasts in odontomas (25). The expression of podoplanin in both normal developmental tooth germ and odontogenic tumors suggests a role of the protein in morphological changes and/or cell migration. Accumulation of samples for further study will be necessary.

In CP, expression of podoplanin was observed in all cases of the adamantinomatous type and squamous type. Immunoreactivity for podoplanin was observed mainly in the middle layer of the adamantinomatous type, but in the basal layer of the squamous type. There was a significant difference in the location of podoplanin expression between adamantinomatous-type and squamous-type CP. Embryologically (44), the adenohypophysis arises from the oral ectoderm (stomoderm) that later develops into the enamel organs and oral mucosa. Rathke's pouch evolves from the roof of the stomoderm, and the anterior wall of the pouch proliferates into the primordium of the adenohypophysis, and then subsequently differentiates into the secretory mass known as the anterior lobe of the pituitary gland (45). The remaining stomoderm develops into enamel organs through the tooth buds and the oral mucosa of nonkeratinized squamous epithelium. The histogenesis of ordinary $\mathrm{CP}$ of the adamantinomatous type or squamous type, and Rathke's cleft cyst could also be explained as follows: The anterior wall of Rathke's pouch epithelium fails to evolve into the adenohypophysis and transforms into either enamel organs (adamantinomatous type) or oral mucosa composed of nonkeratinized squamous epithelium (squamous type) (45). In fact, Seemayer et al. (46) have reported a case of pituitary craniopharyngioma with tooth formation. Different abnormalities in the developmental process may influence the different patterns of podoplanin expression in adamantinomatous-type or squamous-type CP. Although the normal oral squamous epithelium is immunonegative for podoplanin, previous studies have shown that lesions associated with severe inflammation (47), dysplasia (14) and carcinoma (12) have focal expression of the protein in the basal epithelial layer or at the proliferating periphery of tumor nests with no expression in the central areas. Podoplanin expression has also been detected in the basal layer of epithelial nests in squamous-type CP. Although no antibody specific for odontogenic epithelium is yet available, the distinctive distribution of podoplanin in squamous-type CP probably reflects a tumor showing unusual differentiation to oral mucosa rather than a focally invasive characteristic.

None of the PM cases examined showed immunoreactivity for podoplanin in any of the epithelial components. In normal skin, podoplanin expression is confined to the basal cell layer of the epidermis, sebaceous glands, and outer root sheath of hairs $(41,48)$. Skin neoplasms, for example some adnexal tumors, squamous cell carcinomas, and basal cell carcinomas, show podoplanin expression (49-51). No expression of podoplanin was detected in tumor nests of PM, but a positive reaction for the protein was observed in osteoblasts or osteocyte-like cells of osseous tissues in the late regressive stage of PM. It has been reported that podoplanin expression is evident in rat osteoblasts and osteocytes (15), although the mechanism responsible for its expression is unknown. Ishige et al. (52) reported that, in PM, production of hair protein and induction of apoptosis may occur at the same time. The reason for the lack of podoplanin expression in PM may be related to apoptosis and unusual hair differentiation.

In conclusion, we have described the expression of podoplanin in three different types of tumors expressing hard $\alpha$-keratin: CCOT, CP and PM. Podoplanin-positive cells were particularly evident in the peripheral layer of tumor nests of CCOT, being apparently related to the neoplastic nature of the tumor, and suggesting a role of 
podoplanin in local invasiveness. In addition, epithelial cells adjacent to ghost cells showed specific staining for podoplanin.

\section{References}

1. Gorlin RJ, Pindborg JJ, Clausen FP, Vickers RA (1962) The calcifying odontogenic cyst-a possible analogue of the cutaneous calcifying epithelioma of Malherbe. An analysis of fifteen cases. Oral Surg Oral Med Oral Pathol 15, 1235-1243.

2. Pindborg JJ, Kramer IRH, Torloni H (1971) Histological typing of odontogenic tumours, jaw cysts, and allied lesions. International histological classification of tumours, World Health Organization, Geneva, 28.

3. Kramer IRH, Pindborg JJ, Shear M (1992) Histological typing of odontogenic tumours. 2nd ed, International histological classification of tumours, Springer-Verlag, Berlin, 20-21.

4. Prætorius F, Ledesma-Montes C (2005) Calcifying cystic odontogenic tumor, Dentinogenic ghost cell tumor. In: Pathology and genetics of head and neck tumours, World Health Organization classification of tumours, Barned L, Eveson JW, Reichart P, Sidransky D eds, IARC Press, Lyon, 313-314.

5. Motosugi U, Ogawa I, Yoda T, Abe T, Sugasawa M, Murata S, Yasuda M, Sakurai T, Shimizu Y, Shimizu M (2009) Ghost cell odontogenic carcinoma arising in calcifying odontogenic cyst. Ann Diagn Pathol 13, 394-397.

6. Yoshida M, Kumamoto H, Ooya K, Mayanagi $\mathrm{H}$ (2001) Histopathological and immunohistochemical analysis of calcifying odontogenic cysts. J Oral Pathol Med 30, 582-588.

7. Gong Y, Wang L, Wang H, Li T, Chen X (2009) The expression of NF- $-\mathrm{B}, \mathrm{Ki}-67$ and MMP-9 in CCOT, DGCT and GCOC. Oral Oncol 45, 515-520.

8. Siqueira AS, Carvalho MR, Monteiro AC, Freitas VM, Jaeger RG, Pinheiro JJ (2010) Matrix metalloproteinases, TIMPs and growth factors regulating ameloblastoma behaviour. Histopathology 57, 128-137.

9. Kato Y, Kaneko M, Sata M, Fujita N, Tsuruo T, Osawa M (2005) Enhanced expression of Aggrus (T1 $\alpha /$ podoplanin), a platelet-aggregation-inducing factor in lung squamous cell carcinoma. Tumour Biol 26, 195-200.

10. Martín-Villar E, Scholl FG, Gamallo C, Yurrita MM, Muñoz-Guerra M, Cruces J, Quintanilla M (2005) Characterization of human PA2.26 antigen (T1 $\alpha-2$, podoplanin), a small membrane mucin induced in oral squamous cell carcinomas. Int $\mathrm{J}$ Cancer 113, 899-910.

11. Dumoff KL, Chu CS, Harris EE, Holtz D, Xu X, Zhang PJ, Acs G (2006) Low podoplanin expression in pretreatment biopsy material predicts poor prognosis in advanced-stage squamous cell carcinoma of the uterine cervix treated by primary radiation. Mod Pathol 19, 708-716.

12. Yuan P, Temam S, El-Naggar A, Zhou X, Liu DD, Lee JJ, Mao L (2006) Overexpression of podoplanin in oral cancer and its association with poor clinical outcome. Cancer 107, 563-569.

13. Nakayama Y, Matsumoto K, Nagato M, Inoue Y, Katsuki T, Minagawa N, Shibao K, Tsurudome Y, Hirata K, Higure A, Sako T, Nagata N (2007) Significance of lymphangiogenesis as assessed by immunohistochemistry for podoplanin in patients with esophageal carcinoma. Anticancer Res 27, 619-625.

14. Kawaguchi H, El-Naggar AK, Papadimitrakopoulou V, Ren H, Fan YH, Feng L, Lee JJ, Kim E, Hong WK, Lippman SM, Mao L (2008) Podoplanin: a novel marker for oral cancer risk in patients with oral premalignancy. J Clin Oncol 26, 354-360.

15. Wetterwald A, Hoffstetter W, Cecchini MG, Lanske B, Wagner C, Fleisch $\mathrm{H}$, Atkinson M (1996) Characterization and cloning of the E11 antigen, a marker expressed by rat osteoblasts and osteocytes. Bone 18, 125-132.

16. Petrova TV, Mäkinen T, Mäkelä TP, Saarela J, Virtanen I, Ferrell RE, Finegold DN, Kerjaschki D, Ylä-Herttuala S, Alitalo K (2002) Lymphatic endothelial reprogramming of vascular endothelial cells by the Prox-1 homeobox transcription factor. EMBO J 21, 4593-4599.

17. Hirakawa S, Hong YK, Harvey N, Schacht V, Matsuda K, Libermann T, Detmar M (2003) Identification of vascular lineage-specific genes by transcriptional profiling of isolated blood vascular and lymphatic endothelial cells. Am J Pathol 162, 575-586.

18. Schacht V, Ramirez MI, Hong YK, Hirakawa S, Feng D, Harvey N, Williams M, Dvorak AM, Dvorak HF, Oliver G, Detmar M (2003) T1 $\alpha /$ podoplanin deficiency disrupts normal lymphatic vasculature formation and causes lymphedema. EMBO J 22, 3546-3556.

19. Schacht V, Dadras SS, Johnson LA, Jackson DG, Hong YK, Detmar M (2005) Up-regulation of the lymphatic marker podoplanin, a mucin-type 
transmembrane glycoprotein, in human squamous cell carcinomas and germ cell tumors. Am J Pathol 166, 913-921.

20. Martín-Villar E, Megías D, Castel S, Yurrita MM, Vilaró S, Quintanilla M (2006) Podoplanin binds ERM proteins to activate RhoA and promote epithelial-mesenchymal transition. J Cell Sci 119, 4541-4553.

21. Wicki A, Lehembre F, Wick N, Hantusch B, Kerjaschki D, Christofori G (2006) Tumor invasion in the absence of epithelial-mesenchymal transition: podoplanin-mediated remodeling of the actin cytoskeleton. Cancer Cell 9, 261-272.

22. Wicki A, Christfori G (2007) The potential role of podoplanin in tumor invasion. Br J Cancer 96, 1-5.

23. González-Alva P, Tanaka A, Oku Y, Miyazaki Y, Okamoto E, Fujinami M, Yoshida N, Kikuchi K, Ide F, Sakashita H, Kusama K (2010) Enhanced expression of podoplanin in ameloblastomas. J Oral Pathol Med 39, 103-109.

24. Okamoto E, Kikuchi K, Miyazaki Y, GonzálezAlva P, Oku Y, Tanaka A, Yoshida N, Fujinami M, Ide F, Sakashita H, Kusama K (2010) Significance of podoplanin expression in keratocystic odontogenic tumor. J Oral Pathol Med 39, 110-114.

25. González-Alva P, Inoue H, Miyazaki Y, Tsuchiya H, Noguchi Y, Kikuchi K, Ide F, Ishihara S, Katayama T, Sakashita H, Kusama K (2011) Podoplanin expression in odontomas: clinico pathological study and immunohistochemical analysis of 86 cases. J Oral Sci 53, 67-75.

26. Janzer RC, Burger PC, Giangaspero F, Paulus W (2000) Craniopharyngioma. In: Pathology and genetics of tumours of the nervous system, World Health Organization classification of tumours, Kleihues P, Cavenee WK eds, IARC Press, Lyon, 244-246.

27. Hurt MA, Kaddu S, Kutzner H, Cribier B, Schulz T, Hartschuh W (2006) Benign tumours with follicular differentiation. In: Pathology and genetics of skin tumours, World Health Organization classification of tumours, Philip EB, Günter B, David W, Alin S eds, IARC Press, Lyon, 153-155.

28. Kusama K, Katayama Y, Oba K, Ishige T, Kebusa Y, Okazawa J, Fukushima T, Yoshino A (2005) Expression of hard $\alpha$-keratins in pilomatrixoma, craniopharyngioma, and calcifying odontogenic cyst. Am J Clin Pathol 123, 376-381.

29. Levy BA (1973) Ghost cell and odontomas. Oral Surg Oral Med Oral Pathol 36, 851-855.

30. Regezi JA, Courtney RM, Kerr DA (1975) Kera- tinization in odontogenic tumors. Oral Surg Oral Med Oral Pathol 39, 447-455.

31. Sedano HO, Pindborg JJ (1975) Ghost cell epithelium in odontomas. J Oral Pathol 4, 27-30.

32. Sapp JP, Gardner DG (1977) An ultrastructural study of the calcifications in calcifying odontogenic cysts and odontomas. Oral Surg Oral Med Oral Pathol 44, 754-766.

33. Kerebel B, Kerebel LM, Furet A (1981) Complex odontoma: a type of hamartoma. Bull Group Int Rech Sci Stomatol Odontol 24, 245-254.

34. Kerebel B, Kerebel LM (1985) Ghost cells in complex odontoma: a light microscopic and SEM study. Oral Surg Oral Med Oral Pathol 59, 371-378.

35. Piattelli A, Trisi P (1991) Ghost cells in compound odontoma: a study of undemineralized material. Bull Group Int Rech Sci Stomatol Odontol 34, 145-149.

36. Hibino T, Fujita E, Tsuji Y, Nakanishi J, Iwaki $\mathrm{H}$, Katagiri C, Momoi T (2010) Purification and characterization of active caspase-14 from human epidermis and development of the cleavage sitedirected antibody. J Cell Biochem 109, 487-497.

37. Kimura N, Kimura I (2005) Podoplanin as a marker for mesothelioma. Pathol Int 55, 83-86.

38. Shibahara J, Kashima T, Kikuchi Y, Kunita A, Fukayama M (2006) Podoplanin is expressed in subsets of tumors of the central nervous system. Virchows Arch 448, 493-499.

39. Ishida M, Kushima R, Okabe H (2008) Immunohistochemical demonstration of D2-40 in basal cell carcinomas of the skin. J Cutan Pathol 35, 926-930.

40. Rodrigo JP, García-Carracedo D, González MV, Mancebo G, Fresno M, García-Pedrero J (2010) Podoplanin expression in the development and progression of laryngeal squamous cell carcinomas. Mol Cancer 9, 48.

41. Zustin J, Scheuer HA, Friedrich RE (2010) Podoplanin expression in human tooth germ tissues and cystic odontogenic lesions: an immunohistochemical study. J Oral Pathol Med 39, 115-120.

42. Imaizumi Y, Amano I, Tsuruga E, Kojima H, Sawa Y (2010) Immunohistochemical examination for the distribution of podoplanin-expressing cells in developing mouse molar tooth germs. Acta Histochem Cytochem 43, 115-121.

43. Sawa Y (2010) New trends in the study of podoplanin as a cell morphological regulator. Jpn Dent Sci Rev 46, 165-172.

44. Yamada H, Haratake J, Narasaki T, Oda T (1995) Embryonal craniopharyngioma. Case report of the 
morphogenesis of a craniopharyngioma. Cancer 75, 2971-2977.

45. Asa SL, Kovacs K, Laszlo FA, Domokos I, Ezrin C (1986) Human fetal adenohypophysis. Histologic and immunocytochemical analysis. Neuroendocrinology 43, 308-316.

46. Seemayer TA, Blundell JS, Wiglesworth FW (1972) Pituitary craniopharyngioma with tooth formation. Cancer 29, 423-430.

47. Miyazaki Y, Okamoto E, González-Alva P, Hayashi J, Ishige T, Kikuchi K, Nemoto N, Shin K, Sakashita H, Ochiai K, Kusama K (2009) The significance of podoplanin expression in human inflamed gingiva. J Oral Sci 51, 283-287.

48. Plaza JA, Ortega PF, Bengana C, Stockman DL, Suster S (2010) Immunolabeling pattern of podoplanin (D2-40) may distinguish basal cell carcinomas from trichoepitheliomas: a clinicopathologic and immunohistochemical study of 49 cases. Am J Dermatopathol 32, 683-687.
49. Gomaa AH, Yaar M, Bhawan J (2007) Cutaneous immunoreactivity of D2-40 antibody beyond the lymphatics. Am J Dermatopathol 29, 18-21.

50. Liang H, Wu H, Giorgadze TA, Sariya D, Bellucci KS, Veerappan R, Liegl B, Acs G, Elentitsas R, Shukla S, Youngberg GA, Coogan PS, Pasha T, Zhang PJ, Xu X (2007) Podoplanin is a highly sensitive and specific marker to distinguish primary skin adnexal carcinomas from adenocarcinomas metastatic to skin. Am J Surg Pathol 31, 304-310.

51. Yang HM, Cabral E, Dadras SS, Cassarino DS (2008) Immunohistochemical expression of D2-40 in benign and malignant sebaceous tumors and comparison to basal and squamous cell carcinomas. Am J Dermatopathol 30, 549-554.

52. Ishige T, Kikuchi K, Miyazaki Y, Hara H, Yoshino A, Terui T, Katayama Y, Kusama K, Nemoto N (2011) Differentiation and apoptosis in pilomatrixoma. Am J Dermatopathol 33, 60-64. 